\title{
OFICINA BEM VIVER - CONSTRUÇÃO DE TECNOLOGIAS E SIGNIFICADOS DE EDUCAÇÃO EM SAÚDE NA ÁREA DA SAÚDE MENTAL ${ }^{*}$
}

\section{Edson Mascarenhas Cotta ${ }^{1}$; Ana Carolina Henriques Oliveira Amaral de Castro ${ }^{1}$; Nadja Cristiane Lappann Botti ${ }^{2}$}

Este trabalho objetivou descrever as tecnologias de Educação em Saúde na Saúde Mental e discutir o processo ensino/aprendizagem da atividade educativa, na Saúde Mental. O estudo é de natureza descritivo-exploratória, referente à experiência dos acadêmicos do $4^{\circ}$ período de Enfermagem, durante a Oficina Bem Viver. Essa oficina foi realizada no $2^{\circ}$ semestre de 2007, no Centro de Convivência da Saúde Mental "Estação dos Sonhos", em Betim, MG. Encontraram-se os significados de atores da Reforma Psiquiátrica, desmistificação do conceito de loucura, mudança subjetiva e promoção em saúde para o cuidar e Educação em Saúde na Saúde Mental, para os acadêmicos de Enfermagem.

Descritores: Educação em Saúde; Enfermagem; Saúde Mental; Promoção da Saúde.

\section{GOOD LIVING WORKSHOP - BUILDING HEALTH EDUCATION TECHNOLOGIES AND MEANINGS IN MENTAL HEALTH ${ }^{\dagger}$}

The purpose of this study is to describe the Health Education technologies used in Mental Health and discuss the teaching-learning process of educative activities in Mental Health. This is a descriptive-exploratory study on the experience of nursing senior students during the "Well Living Workshop". This workshop took place in the second semester of 2007, at the Mental Health Social Center "Dream Station", in Betim (Minas Gerais). We found the meanings of actors of the Psychiatric Reform, demystifying the concept of madness, subjective change and health promotion to care and Health Education in Mental Health for nursing students.

Descriptors: Health Education; Nursing; Mental Health; Health Promotion.

\footnotetext{
*Trabalho agraciado com o segundo lugar (Prêmio Maria Aparecida Minzoni) no X Encontro de Pesquisadores em Saúde Mental e Enfermagem Psiquiátrica. Ribeirão Preto, SP, Brasil, 2008.

${ }^{\dagger}$ This study was second-prize winner (Prize: Maria Aparecida Minzoni) in the $10^{\text {th }}$ Meeting of Researchers in Mental Health and Psychiatric Nursing. Ribeirão Preto, 2008.

1-Bacharel em Administração. Aluno do curso de Graduação em Enfermagem, Pontifícia Universidade Católica, Betim, MG, Brasil. E-mail: Edson - guipados@yahoo.com.br , Ana Carolina castro_anacarolina@yahoo.com.br

2-Enfermeira, Psicóloga, Doutor em Enfermagem Psiquiátrica. Professor Adjunto, Universidade Federal São João del-Rei, Divinópolis, MG, Brasil.E-mail: nadjaclb@terra.com.br
}

Autor Correspondente: Nadja Cristiane Lappann Botti. Endereço para Correspondência: Universidade Federal de São João del-Rei, Rua Sebastião Gonçalves Coelho, 400, Bairro Chanadour, CEP 35501-296, Divinópolis, MG, Brasil.E-mail:nadjaclb@terra.com.br 


\section{TALLER BUEN VIVIR - CONSTRUCCIÓN DE TECNOLOGÍAS Y SIGNIFICADOS DE EDUCACIÓN} EN SALUD EN EL ÁREA DE LA SALUD MENTAL ${ }^{\ddagger}$

Este trabajo objetiva describir las tecnologías de Educación en Salud en la Salud Mental y discutir el proceso enseñanza-aprendizaje de la actividad educativa en Salud Mental. El estudio es de carácter descriptivo-exploratorio de la experiencia de los académicos del $4^{\circ}$ período de Enfermería durante el "Taller Buen Vivir". Este taller fue realizado en el $2^{\circ}$ semestre de 2007, en el Centro de Convivencia de Salud Mental "Estación de los Sueños", en Betim (MG). Encontramos los aportes de actores de la Reforma Psiquiátrica, desmitificación del concepto de locura, cambio subjetivo y promoción en salud para el cuidado y Educación en Salud en la Salud Mental para los académicos de Enfermería.

Descriptores: Educación para la Salud, Enfermería, Salud Mental; Promoción de la Salud. 


\section{Introdução}

As atividades constituem um modo de trabalho em saúde que se pode denominar, de modo geral, tecnologias. Tecnologia refere-se ao saber prático ou habilidade humana de fabricar, construir e utilizar instrumentos, parte originária do cotidiano, no nível da própria atividade empírica, e parte originária da necessidade de se estabelecerem procedimentos sistematizados para a operacionalização de uma atividade prática ${ }^{(1)}$. Na saúde mental, as tecnologias se revelam no próprio processo de trabalho, onde se articulam o conjunto de saberes, instrumentos e práticas ${ }^{(2)}$.

Com a reforma psiquiátrica e o paradigma psicossocial, se tornou imperativo a criação de novos serviços e de novas tecnologias no cuidado do sofrimento psíquico, objetivando a reabilitação psicossocial. Entende-se a reabilitação psicossocial como processo que gera oportunidades às pessoas com sofrimento psíquico alcançar autonomia e melhor qualidade de vida na comunidade. Portanto, aponta para a redução de estigma e preconceito e visa promover equidade e oportunidade para os usuários da saúde mental ${ }^{(3)}$.

Nos serviços substitutivos de saúde mental, a criação de tecnologias para o cuidar deve articular a existência singular do sofrimento psíquico em seu meio familiar e social, a partir da capacidade do próprio serviço e da comunidade. Para que isso ocorra, o profissional de saúde necessita 
compreender a demanda por novas tecnologias de cuidar e o contexto inovador e criativo em que se insere a assistência em saúde mental. Uma prática que tem na produção da subjetividade, no imaginário social e na criatividade dispositivo singular para a promoção de cuidados e qualidade de vida ${ }^{(4)}$.

Considerando o movimento da reforma psiquiátrica, é importante ressaltar que a mudança do modelo de assistência em saúde mental não implica apenas em implantação de serviços substitutivos, mas se torna imprescindível modificação da prática profissional asilar por prática pautada no modelo psicossocial $^{(5)}$. Entre os desafios a serem enfrentados pelo movimento da reforma se encontra a formação dos recursos humanos da área da saúde ${ }^{(6)}$. Nesse sentido, o ensino da disciplina Saúde Mental e Psiquiatria do curso de enfermagem da PUC Minas - Betim visa contribuir para a formação do profissional enfermeiro, a partir dos pressupostos da reforma psiquiátrica brasileira $^{(7)}$ e do paradigma psicossocial $^{(5)}$, sendo que, no trabalho cotidiano dos serviços de saúde mental, se abrem, paulatinamente, outros campos de intervenção que requerem a aquisição de novas competências ${ }^{(8)}$.

A partir da aprovação da $\operatorname{LDB}^{(9)}$, Lei n. 9394/96, os projetos políticos pedagógicos dos cursos de enfermagem possibilitaram flexibilização dos currículos e, nesse sentido, ousar na construção de experiências acadêmicas criativas e inovadoras. Outro aspecto que merece referência diz respeito ao ensino por competência, que privilegia pensar criticamente a realidade, com vistas a transformá-la. E, assim sendo, ressalta a importância de proposta metodológica de 
ensino que trabalhe na perspectiva do paradigma ação/reflexão/ação ${ }^{(10)}$.

A partir dessas considerações, foi proposta para os acadêmicos, entre outras atividades do ensino clínico de Saúde Mental e Psiquiatria, a construção de tecnologias inovadoras de cuidar em saúde mental a serem desenvolvidas no Centro de Convivência da Saúde Mental “Estação dos Sonhos”, na atividade de educação em saúde nomeada Oficina Bem Viver.

Sendo assim, o presente estudo tem como objetivos:

- $\quad$ descrever as tecnologias de cuidar em educação em saúde na área da saúde mental, criadas pelos acadêmicos de enfermagem, durante a realização da Oficina Bem Viver;

- discutir o processo ensino/aprendizagem na área da saúde mental, a partir dos significados da realização da Oficina Bem Viver, para os acadêmicos de enfermagem;

- discutir o processo de reabilitação psicossocial, a partir dos significados da Oficina Bem Viver, para os usuários da saúde mental, segundo os acadêmicos de enfermagem.

\section{Metodologia}

O estudo é de natureza descritivoexploratória da experiência dos acadêmicos de enfermagem, durante a atividade educativa Oficina Bem Viver. Essa oficina foi realizada no período de 5 de agosto a 21 de novembro de 2007, no Centro de Convivência da Saúde Mental, em Betim. A Oficina acontecia às segundas e quartas-feiras, no turno manhã 
e tarde, com a participação dos acadêmicos matriculados no $4^{\circ}$ período do turno tarde e noite.

A Oficina Bem Viver apresenta a concepção de oficina de educação em saúde temática, desenvolvida através de dinâmicas de grupo (apresentação, sensibilização e encerramento), jogos educativos e vivências temáticas. Os temas abordados foram: alimentação saudável, alcoolismo, saúde sexual, beleza, prevenção de câncer de mama e colo de útero, hipertensão, diabetes, higiene bucal, obesidade, tabagismo, osteoporose, higiene pessoal, atividade física, relacionamento interpessoal (autoestima e convivência).

A investigação dos significados da realização da Oficina Bem Viver, para os acadêmicos, foi realizada a partir de um questionário de avaliação, composto por 3 questões norteadoras e apresentado no final do semestre. Responderam ao questionário 107 acadêmicos. O referencial metodológico utilizado, para tabular as respostas do questionário, foi o Discurso do Sujeito Coletivo (DSC) ${ }^{(11)}$. Tecnologias inovadoras de cuidar em Educação em Saúde na área da Saúde Mental

Para a construção das tecnologias educativas de cuidar, na área da saúde mental, partiu-se da definição de educação e promoção em saúde. Educação em Saúde, entendida como combinações de experiências de aprendizagem, delineadas com vistas a facilitar ações voluntárias, referentes à saúde; e promoção em saúde como combinação de apoios educacionais e ambientais que visam atingir ações e condições conducentes à saúde ${ }^{(12)}$. 
A Oficina Bem Viver, enquanto processo educativo, apresentava como objetivo comum o incentivo à prática de hábitos saudáveis e mudanças no estilo de vida, através de recursos lúdicos, visando o cuidado com a saúde. Na definição de atividade lúdica enquadra-se qualquer atividade que produza distanciamento da realidade, estimule a autoexpressão dos participantes, leve ao relaxamento das tensões e, ainda, proporcione entretenimento e reconhecimento de si $\operatorname{mesmo}^{(13)}$.

Na Oficina, adotou-se, como metodologia de trabalho, o planejamento participativo (professor e acadêmicos), anteriormente à aplicação em campo dos próprios jogos educativos e vivências temáticas. $\quad$ A $\quad$ comunicação professor/aluno torna-se, portanto, a base do processo de ensino ${ }^{(14)}$. O planejamento sobre a atividade a ser realizada deve ser bem estruturado, pensando sempre no ambiente e nos recursos materiais e humanos, a serem utilizados. Além disso, partiu-se da premissa que se deve estimular enfermeiros da área de saúde mental a utilizar atividades não tradicionais, as quais possam complementar e melhorar a assistência já prestada ao portador de transtorno mental $^{(15)}$.

A partir da questão norteadora Quais os aspectos facilitadores na experiência acadêmica da Oficina Bem Viver?, encontraram-se os significados referentes ao espaço e sujeitos participantes da oficina educativa, isto é, o espaço (físico e humano) do Centro de Convivência e a particular participação dos usuários da saúde mental.

A estrutura física é ponto importante, pois no Centro de Convivência o espaço é adequado e agradável. Também, a abertura e a liberdade do Centro de Convivência são 
essenciais para um contato mais direto com o usuário. Importante também que os profissionais e voluntários nos receberam com boa vontade, demonstrando adesão, interesse em participar das oficinas e preocupação com o bem-estar dos usuários $\left(\mathrm{DSC}_{10}\right)$.

O Centro de Convivência foi escolhido como cenário por ser um serviço que apresenta sintonia com os pressupostos da reforma psiquiátrica e do SUS. Inaugurado em 2001, funciona como dispositivo da saúde mental que tem por objetivo possibilitar a convivência e resgatar a cidadania do portador de sofrimento mental, através de um universo múltiplo de atividades, eventos, oficinas, vivências do cotidiano e grupos de geração de trabalho e renda. Assim, o Centro de Convivência, na rede de atenção à saúde mental, possui papel diferenciado e estratégico para os outros serviços da rede e para a comunidade em geral, tornando-se, assim, fundamental no processo da reabilitação psicossocial.

Os usuários desse serviço realizam tratamento na rede de atenção à saúde mental do município de Betim (UBS ${ }^{\dagger}$, CERSAM $^{\ddagger}$ e CERSAMi ${ }^{\S}$ ). São encaminhados por profissionais da área da saúde mental referências do tratamento, por equipes de saúde da família, ou surgem no serviço por livre demanda. Em geral, os usuários, além do transtorno mental específico, apresentam questões relacionadas à apatia, inatividade, isolamento, dificuldade de convívio e inexistência de laços sociais e/ou familiares.

Também foram encontrados como facilitadores do processo, para os acadêmicos, os significados referentes à metodologia do trabalho.

Os temas escolhidos foram apresentados através de atividades, dinâmicas, jogos e

\footnotetext{
† Unidade Básica de Saúde

‡ Centro de Referência em Saúde Mental

$\S$ Centro de Referência em Saúde Mental Infantil
} 
SMAD, Rev. Eletrônica Saúde Mental Álcool Drog. (Ed. port.) 2010 Nov; 6(Especial):471-92

estratégias, relacionadas ao cotidiano, e que refletem na saúde dos usuários, neste sentido, também incentivam a autonomia. Por exemplo, na oficina da Alimentação Saudável, nesta lógica, os usuários também são cidadãos que fazem compras e escolhem o que vão comer, além deles próprios fazerem sua comida ( $\mathrm{DSC}_{9}$ ).

Outro significado encontrado, como facilitador para os acadêmicos, durante a Oficina Bem Viver, foi o trabalho em equipe, associado à orientação do professor.

Alguns integrantes do grupo apresentaram facilidade de comunicação $e$ dominavam o assunto. Além disso, outros fatores como a interação e união do grupo, comprometimento, expectativa quanto aos resultados e aceitação pelos usuários quanto às atividades propostas, vontade de vivenciar $e$ identificar os assuntos e casos abordados em sala de aula possibilitou um trabalho em equipe, contribuindo para o sucesso das oficinas $\left(\mathrm{DSC}_{8}\right)$

Acredita-se, aqui, que o trabalho em equipe dos acadêmicos deve ser valorizado durante a práxis acadêmica/profissional, pois, dessa forma, há implicação no processo de trabalho, atuando como sujeito. É importante que o professor valorize o diálogo, a troca, a relação interpessoal, acreditando que é possível aprender conversando, discutindo e trocando ideias com seus aprendizes ${ }^{(14)}$. Já, da parte dos acadêmicos, é esperada atitude ativa em busca do saber, com a extração da informação do ambiente, integrando-a a outras armazenadas na memória, fundamentando, assim, seu questionamento junto ao professor. Por esse viés, os educadores estimulam o aluno a tomar decisões, fazer observações, perceber relações e trabalhar com hipóteses. Dessa forma, o professor facilita ao estudante que incremente o seu poder (empowerment), ou seja, desenvolva habilidades e atitudes, 
conducentes à aquisição de poder técnico (saber) e político para atuar em prol da sociedade (no caso da Enfermagem, pela saúde humana).

Os significados de cuidar em Educação em Saúde na área da Saúde Mental, para os acadêmicos de Enfermagem

A partir da questão norteadora $\mathrm{O}$ que significou a experiência acadêmica da Oficina Bem Viver?, encontraram-se os significados de atores da reforma psiquiátrica, desmistificação do conceito de loucura, mudança subjetiva e promoção em saúde.

A educação é uma possibilidade de transformação, centrada no desenvolvimento da consciência crítica, levando o enfermeiro à reflexão sobre a prática profissional e ao compromisso com a sociedade ${ }^{(16)}$. Nesse sentido, a ideia de atores da reforma para os acadêmicos encontra-se em sintonia com o paradigma psicossocial $^{(5)}$ e com a LDB.

Forma de pôr em prática conceitos defendidos na Reforma Psiquiátrica, contribuindo com as mudanças, tendo o privilégio de sermos os atores da história, superando as teorias que havíamos aprendido em sala de aula ( $\left.\mathrm{DSC}_{4}\right)$.

A LDB visa a formação de profissionais que possam vir a ser críticos, reflexivos, dinâmicos, ativos, diante das demandas do mercado de trabalho, aptos para aprender a aprender, a assumir os direitos de liberdade e cidadania, enfim, compreender as tendências do mundo atual e as necessidades de desenvolvimento do país ${ }^{(16)}$. Portanto, acredita-se que o discurso enunciado acima revela essa sintonia.

Sabe-se que, no Brasil, a partir dos anos 70, iniciou-se o processo de crítica ao modelo hospitalocêntrico de 
SMAD, Rev. Eletrônica Saúde Mental Álcool Drog. (Ed. port.) 2010 Nov; 6(Especial):471-92

assistência ao sofrimento mental e à definição de estratégias e rumos na implementação da reforma psiquiátrica. Essa reforma nasceu com o objetivo de superar o estigma, a institucionalização e a cronificação dos doentes mentais ${ }^{(15)}$. A ideia de atores da reforma dos acadêmicos representa consciência crítica e sensibilização com os pressupostos do movimento da luta antimanicomial, importante na formação profissional da enfermagem, enquanto profissional da saúde.

Outro significado encontrado da experiência acadêmica foi a desmistificação do conceito de loucura.

A experiência da Oficina Bem Viver trouxe uma reforma nos nossos pensamentos $e$ conceitos acerca da loucura, pois tínhamos muito medo de como seríamos recebidos pelos usuários. Deixamos de lado o preconceito, medo e a ideia de periculosidade, abolindo estigmas e mudando radicalmente a forma de encarar os usuários.
Aprendemos ter mais sensibilidade com as pessoas e a olhar o mundo com olhos mais humanizados. Também contribuiu para nos mostrar que os usuários são cidadãos, inteligentes, que não perderam sua capacidade de raciocínio e memória, enfim, para nós; enfermeiros em formação; proporcionou um enorme aprendizado não só sobre a disciplina, mas sobre a vida, importante para acreditar que mudar é possível e preciso ( $\left.\mathrm{DSC}_{5}\right)$.

Entende-se que, a partir da desmistificação do conceito de loucura, há possibilidade da construção de nova prática da enfermagem na atenção à saúde mental, rompendo o histórico papel de controlar, vigiar e punir, prática revelada no cuidado humanístico, ético e terapêutico. Por esse viés, concorda-se, aqui, que o cuidado oferecido ao psicótico deve respeitar e acolher a diferença, pois ele deve ser percebido como sujeito humano e não como sintoma a ser debelado; além disso, o exercício da ousadia, da criatividade e da alegria deve 
estar sempre associado à atividade terapêutica $^{(17)}$.

Para atender às exigências da nova LDB, surgiram as Diretrizes Curriculares Nacionais dos cursos de saúde que têm como objetivos "levar os alunos dos cursos de graduação em saúde a aprender a aprender que engloba aprender a ser, aprender a fazer, aprender a viver juntos e aprender a conhecer”(9).

A mudança subjetiva dos acadêmicos, em relação ao portador de sofrimento mental, foi mais um significado encontrado para a experiência acadêmica da Oficina Bem Viver.

O principal dificultador foi quebrar o nosso preconceito e medo de trabalhar com o diferente, pois não sabíamos a reação dos usuários. Era difícil imaginar formas de trabalhar, pois o imaginário social estava muito presente, nos deixando na expectativa com relação ao entendimento, aceitação, se ficariam bravos ou tristes, medo da erotização e agressão, mas o contato direto superou nossas expectativas, encontramos pessoas cativantes, interessantes $e$ conseguimos ver além do distúrbio, enxergamos o ser humano, ampliando nossa visão acerca de nossas futuras ações como enfermeiros (DSC 11 ). Para os acadêmicos de enfermagem da PUC Minas - Betim é no $4^{\circ}$ período que se inicia a práxis acadêmica/profissional com as atividades propostas pelo ensino clínico. Essa questão, associada à área específica da saúde mental, nos remete aos sinais de ansiedade, medo e angústia que os estudantes apresentam no início do aprendizado prático. Quando se encontra o significado de mudança subjetiva dos acadêmicos, em relação à saúde mental e se sabendo da importância da compreensão do significado das primeiras experiências para o aluno, o contato com o novo, com o diferente, com o contraditório é percebido pelos jovens com muita intensidade. De maneira geral, as pessoas sentem medo do novo, na 
enfermagem, a relação vivenciada do cuidar, no início da prática profissional, é considerada como "algo novo", e tal situação transforma a fase de aquisição de conhecimento em momentos de apreensão e medo ${ }^{(14)}$.

Também encontrou-se a ideia de promoção em saúde para a experiência dos acadêmicos.

Trabalho de educação em saúde com o intuito de promover a saúde, através de temas relevantes e atuais como tabagismo, obesidade, sexualidade, dentre outros, de forma dinâmica, participativa, agradável e atrativa. Ficou claro como o profissional pode interagir com os usuários e contribuir para uma melhor qualidade de vida $\left(\mathrm{DSC}_{3}\right)$.

Importante significado, pois se reconhece que a assistência não pode se ater somente nos aspectos da doença mental, pois os fatores que concorrem para o bem-estar do portador de sofrimento mental ultrapassam esses $\operatorname{aspectos}^{(18)}$. Acredita-se, aqui, na formação de profissionais de enfermagem críticos, reflexivos e com competência profissional para participar, efetivamente, da resolução dos problemas de saúde, para além da saúde mental, dos portadores de sofrimento psíquico.

Foi premissa de trabalho, durante o processo educativo da Oficina Bem Viver, considerar o contexto dos usuários e do meio em que eles vivem, pois se reconhece que os processos educativos buscam a passagem do estado de desconhecimento relativo para o estado de conhecimento capaz de transformar a realidade $^{(16)}$. Outra premissa metodológica foi estabelecer relação horizontalizada entre acadêmicos e usuários, através da comunicação bilateral e dialógica, onde ambos contribuem, cada qual à sua maneira, para a construção do conhecimento. Tais processos ocorrem 
com base no contexto de vida das pessoas, do cotidiano, das suas experiências e devem ter como propósito libertar as pessoas para que possam ser sujeitos sociais, capazes de fazer opções construtivas para suas vidas e para a sociedade $^{(19)}$.

A população, de forma geral, exibe estereótipos e preconceitos em relação ao portador de sofrimento mental, como pessoa que não raciocina, agressiva, estranha, perigosa, incurável, que traz problemas para a família e, portanto, deve ficar no hospício. Os alunos iniciantes, no curso de enfermagem, trazem consigo representações semelhantes, demonstrando desconhecimento, tanto com relação ao transtorno mental quanto em relação à recuperação, ou possibilidades de convivência, do portador de sofrimento mental em seu meio social ${ }^{(20)}$.
Reconhece-se, aqui, que esses estigmas podem influenciar, de forma negativa, as condutas que os acadêmicos terão com os usuários em questão e, no futuro, enquanto profissionais. Portanto, se esses aspectos não são contemplados adequadamente, durante a formação, têm grandes chances de se traduzirem em atitudes autoritárias ou benevolentes (paternalistas), implicando no agir de modo não terapêutico ${ }^{(20)}$. Nesse sentido, os significados de atores da reforma psiquiátrica, desmistificação do conceito de loucura, mudança subjetiva e promoção da saúde, encontrados para a experiência acadêmica da Oficina Bem Viver, se revelam como importantes, pelo fato de serem, para a maioria dos acadêmicos, a primeira experiência na saúde mental, serviços e usuários e, portanto, poder revelar uma nova práxis profissional. Esses aspectos têm 
SMAD, Rev. Eletrônica Saúde Mental Álcool Drog. (Ed. port.) 2010 Nov; 6(Especial):471-92

importância ímpar devido ao fato de que o aluno de enfermagem, tendo oportunidades para oferecer assistência de forma holística, quando se tornar profissional, poderá adequar-se melhor a um trabalho multiprofissional e de forma desburocratizada $^{(20)}$.

Os significados da Educação em Saúde para os usuários da Saúde Mental, segundo os acadêmicos de Enfermagem

A partir da questão norteadora $\mathrm{O}$ que significou para os usuários da Saúde Mental a experiência da Oficina Bem Viver?, apresentada aos acadêmicos, encontraram-se dois significados: primeiro a ideia de convivência, aprendizagem e diversão, e, segundo, de melhoria da qualidade de vida.

A Oficina Bem Viver significou para os usuários momento de interação com os acadêmicos e uns com os outros, trazendo novas experiências, esclarecendo dúvidas, estreitando os laços e convivendo com as diferenças. Também uma forma diferente de aprender temas importantes compartilhando saberes $e$ expressando vontades e sentimentos, incentivando a autonomia. Além de ser uma estratégia de diversão e ocupação (DSC 1 ).

Quando se reconhece que o processo ensino/aprendizagem em enfermagem deve buscar uma reorientação para além da aquisição de conhecimentos e o desenvolvimento de habilidades técnicas ${ }^{(16)}$, se torna imperativa a construção de um processo ensino/aprendizagem que permita o desenvolvimento de habilidades sociais e ação crítica e ética, que possam impulsionar o rompimento com os paradigmas asilar e biomédico. Nesse sentido, entende-se que o significado de convivência, aprendizagem e diversão para os usuários que participaram da Oficina refletem habilidades sociais e de 
SMAD, Rev. Eletrônica Saúde Mental Álcool Drog. (Ed. port.) 2010 Nov; 6(Especial):471-92

ação crítica e ética dos acadêmicos, entendidas como importantes ferramentas da reabilitação psicossocial. As práticas comunitárias, amparadas no campo psicossocial, afirmam os direitos de cidadania, o tratamento como direito, a autonomia dos sujeitos $^{(17)}$.

Nesse novo paradigma de atenção à saúde mental, há o desafio ético de ruptura com os paradigmas asilar e biomédico. Assim, cabe aos serviços de saúde mental proporcionar atividades de lazer aos usuários, familiares e outras pessoas, para que compartilhem de novos espaços sociais, onde possam fluir relações afetivas, para que a sociedade aprenda a conviver com a diferença. Além disso, as práticas assistenciais devem potencializar a subjetividade, a autoestima, a autonomia e a cidadania e devem superar a relação de tutela e a institucionalização/cronificação ${ }^{(15)}$.
O significado de qualidade de vida é encontrado no trecho abaixo.

A oficina aborda diversos temas em saúde de importante significado, colaborando para a melhoria da qualidade de vida não somente no Centro de Convivência, mas na sua casa e comunidade, pois o usuário leva para a casa e cotidiano algumas mudanças. Nestas oficinas os usuários se sentem mais valorizados, há crescimento coletivo e individual contribuindo para a autoestima, o contato social sendo essencial como meio de inserção social $e$ cidadania $\left(\mathrm{DSC}_{2}\right)$.

Historicamente, a psiquiatria não considerava o paciente como sujeito ativo do seu tratamento, não envolvia a sua família e não valorizava a sua história, cultura, vida cotidiana e qualidade de vida, assim, o principal foco de atenção era a doença ${ }^{(15)}$. A partir da reforma psiquiátrica, os serviços de atenção à saúde mental têm enfatizado que o sofrimento mental apresenta prognóstico mais otimista se o usuário for tratado na 
comunidade onde vive e adoeceu, por isso, atualmente, tem aumentado o interesse pela qualidade de vida do portador de sofrimento mental tratado na comunidade ${ }^{(18)}$.

A qualidade de vida vem sendo definida por fatores objetivos e subjetivos que contribuem para o bem-estar e para o atendimento das necessidades humanas $^{(18)}$. A qualidade de vida do portador de sofrimento mental é reflexo do cuidado que ele recebe ,e, assim sendo, esse tema deve ser incluído na avaliação e no planejamento da assistência.

A educação em saúde é um trabalho dirigido para atuar sobre o conhecimento das pessoas, para que elas desenvolvam juízo, crítica e capacidade de intervenção sobre suas vidas e sobre o ambiente com o qual interagem e, assim, criarem condições para se apropriarem de sua existência ${ }^{(19)}$. Em última instância, entende-se que a educação em saúde, na área da saúde mental, possibilita melhora da qualidade de vida, cidadania e ação social dos usuários. Nesse sentido, a prática busca a ampliação da capacidade de entendimento e a apropriação do controle do processo saúde/doença pelo usuário, a ampliação da sua capacidade para agenciar soluções no campo afetivo, material e social, e maior participação na vida política e jurídica ${ }^{(17)}$.

No paradigma asilar, sob a égide da tutela, segregação e exclusão social, o cuidado da enfermagem era pautado na prática do controlar, vigiar e punir, assim, durante muitos anos, o objetivo da enfermagem foi o controle dos sujeitos sociais. Com a reforma psiquiátrica e a mudança de paradigma, a enfermagem assume o compromisso com a qualidade de vida cotidiana do indivíduo em 
sofrimento psíquico. O enfermeiro está cada dia mais atuante e consciente de seu novo papel e tem condição de explorar diversas modalidades terapêuticas no desempenho de sua atividade profissional, colocando em prática alternativas de cuidado, para que mantenham o exercício de sua autonomia e cidadania, enfim, os efeitos da reabilitação psicossocial ${ }^{(15)}$.

\section{Considerações Finais}

A ruptura com o paradigma asilar de assistência à saúde do portador de sofrimento mental deve se iniciar nas escolas formadoras. A mudança do modelo de atenção vem sendo proposta desde a reforma psiquiátrica, mas, ainda hoje, encontram-se pacientes vindos de longas internações, mostrando que o modelo hospitalocêntrico ainda existe no país. A assistência deve priorizar a reabilitação psicossocial, que inclui a inserção do usuário na comunidade, no contexto familiar e no mercado de trabalho, a partir do referencial da reforma psiquiátrica e do paradigma psicossocial. A assistência não pode se ater somente aos aspectos do sofrimento mental, pois os fatores que concorrem para o bem-estar ultrapassam esses aspectos.

Nesse sentido, foram propostas tecnologias inovadoras para o cuidar em educação em saúde, através da Oficina Bem Viver, incentivando a prática de hábitos saudáveis e mudanças no estilo de vida, objetivando o cuidado voltado à saúde.

Pela análise dos resultados obtidos, através dos discursos síntese, pode-se perceber, nos acadêmicos, consciência crítica e sensibilização com 
SMAD, Rev. Eletrônica Saúde Mental Álcool Drog. (Ed. port.) 2010 Nov; 6(Especial):471-92

os pressupostos do movimento da luta antimanicomial, construindo nova prática da enfermagem na saúde mental, que considera o contexto de vida das pessoas, dos seus cotidianos e das suas experiências.

Sendo assim, espera-se incentivar a implementação de novas tecnologias para o cuidado integral do portador de sofrimento mental, tanto pelos profissionais de saúde quanto pelas instituições formadoras que precisam construir tecnologias inovadoras de cuidar em saúde mental, dando aos alunos condições para que explorem diversas modalidades terapêuticas não tradicionais no enfrentamento do transtorno psíquico.

\section{Referências}

1. Nietsche E. Tecnologia emancipatória. Rio Grande do Sul: Ed.UNIJUI; 2000.

2. Ministério da Saúde (BR). $2^{\mathrm{a}}$ Conferência nacional de saúde mental. Brasília (DF): Ministério da Saúde; 1994.

3. Hirdes A. Reabilitação psicossocial: dimensões teórico-práticas do processo. Erechim: ediFAPES; 2001.

4. Tavares C. A poética do cuidar na enfermagem psiquiátrica. Rio de Janeiro: SENAI; 2000.

5. Costa-Rosa A. O modo psicossocial: um paradigma das práticas substitutivas ao modo asilar. In: Amarante P, organizador. Ensaios- 
subjetividade, saúde mental e sociedade.

Rio de Janeiro: FIOCRUZ,; 2000. p. 141-

68.

6. Silva JF Filho, Leibing AG. A Psiquiatria, sua história e seu futuro no Brasil. In: Albuquerque P, Libério M. Práticas ampliadas em saúde mental: desafios e construções do cotidiano. Rio de Janeiro: IPUB/UFRJ; 1999. p. 13.

7. Amarante P. Loucura, cultura e subjetividade: conceitos e estratégias, percursos e atores da reforma psiquiátrica brasileira. In: Fleury S, organizador. Saúde e Democracia: a luta do CEBES. São Paulo: Lemos Editora; 1997. p. 16385.

8. Rotelli F. A instituição inventada. In: Nicácio MF. Desinstitucionalização. São Paulo: Hucitec; 1990. p. 89-99.

9. Conselho Nacional de Educação (BR). Câmara de Educação
Superior. Resolução CNE/CES N. 3, de 07 de novembro de 2001. Institui as Diretrizes Curriculares Nacionais do curso de graduação em enfermagem. Diário Oficial da República Federativa da União. Brasília, 09 nov. 2001. Seção 1, p. 37.

10. Germano RM. O ensino de enfermagem em tempos de mudança. Rev Bras Enferm. 2003;56(4):365-8.

11. Lefévre F, Lefévre AMC. Os novos instrumentos no contexto da pesquisa qualitativa. In: Lefévre $\mathrm{F}$, Lefévre AMC, Teixeira JJ, organizadores. O discurso do sujeito coletivo: uma nova abordagem metodológica em pesquisa qualitativa. Caxias do Sul: EDUCS; 2000. p. 11-35.

12. Candeias NMF. Conceitos de educação e de promoção em saúde: mudanças individuais e mudanças organizacionais. Rev Saúde Pública. 
1997;31(2):209-13.

13. Rabelo SE, Padilha MICS A atividade lúdica no processo educativo ao cliente diabético adulto. Texto Contexto Enferm. 1998;3(7):106-17.

14. Scherer, ZAP; Scherer, EA; Carvalho, AMP. Reflexões sobre o ensino da enfermagem e os primeiros contatos do aluno com a profissão. Rev. LatinoAm. Enfermagem. março-abril 2006;14(2):285-91.

15. Andrade RLP, Pedrão LJ. Algumas considerações sobre a utilização de modalidades terapêuticas não tradicionais pelo enfermeiro na assistência de enfermagem psiquiátrica. Rev. Latino-Am. Enfermagem. set-out 2005;13(5):737-42.

16. Ito EE, Peres AM, Takahashi RT, Leite MMJ. O ensino de enfermagem e as diretrizes curriculares nacionais: utopia x realidade. Rev Esc Enferm USP.
2006;40(4):570-5.

\section{Silva ALA, Fonseca RMGS.}

Os nexos entre concepção do processo saúde/doença mental e as tecnologias de cuidados. Rev. Latino-Am. Enfermagem. nov-dez 2003; 11(6):800-6.

18. Galera SAF, Teixeira MB. Definindo qualidade de vida de pessoas portadoras de problemas de saúde mental. Rev. Latino-Am. Enfermagem. Maio 1997;5(n.esp):69-75.

19. Ruiz VR, Lima AR, Machado AL. Educação em saúde para portadores de doença mental: relato de experiência. Rev Esc Enferm USP. 2004;38(2):190-6.

20. Avanci RC, Malaguti SE, Pedrão LJ. Autoritarismo e benevolência frente à doença mental: estudo com alunos ingressantes no curso de enfermagem. Rev. Latino-Am. Enfermagem. julho-ago 2002;10(4):50915. 


\section{Como citar este artigo:}

Cotta EM, Castro EM, Botti NCL. Oficina Bem Viver - Construção de tecnologias e significados de educação em saúde na área da saúde mental. SMAD, Rev. Eletrônica Saúde Mental Álcool Drog. (Ed. port.) [Internet]. 2010 [acesso: dia mês abreviado com ponto ano]; 6(Especial):471-92. Disponível em: Endereço Eletrônico Visitado. 